\title{
Clinical transition for adolescents with developmental disabilities in Hong Kong: a pilot study
}

\author{
Tamis W Pin *, Wayne LS Chan, CL Chan, KH Foo, Kevin HW Fung, LK Li, Tina CL Tsang
}

\section{A B S T R A C T}

Introduction: Children with developmental disabilities usually move from the paediatric to adult health service after the age of 18 years. This clinical transition is fragmented in Hong Kong. There are no local data for adolescents with developmental disabilities and their families about the issues they face during the clinical transition. This pilot study aimed to explore and collect information from adolescents with developmental disabilities and their caregivers about their transition from paediatric to adult health care services in Hong Kong.

Methods: This exploratory survey was carried out in two special schools in Hong Kong. Convenient samples of adolescents with developmental disabilities and their parents were taken. The questionnaire was administered by interviewers in Cantonese. Descriptive statistics were used to analyse the answers to closed-ended questions. Responses to open-ended questions were summarised.

Results: In this study, 22 parents (mean age \pm standard deviation: $49.9 \pm 10.0$ years) and 13 adolescents (19.6 \pm 1.0 years) completed the faceto-face questionnaire. The main diagnoses of the adolescents were cerebral palsy (59\%) and cognitive impairment (55\%). Of the study parents, $77 \%$ were reluctant to transition. For the 10 families who did move to adult care, $60 \%$ of the parents were not satisfied with the services. The main reasons were reluctant to change and dissatisfaction with the adult medical service. The participants emphasised their need for a structured clinical transition service to support them during this challenging time.

Conclusions: This study is the first in Hong Kong to present preliminary data on adolescents with developmental disabilities and their families during transition from paediatric to adult medical care. Further studies are required to understand the needs of this population group during clinical transition.

\section{Hong Kong Med J 2016;22:445-53 DOI: $10.12809 / \mathrm{hkmj} 154747$}

TW Pin *, PhD

WLS Chan, PhD

CL Chan, BSc (Hons) Physiotherapy

KH Foo, BSc (Hons) Physiotherapy

KHW Fung, BSc (Hons) Physiotherapy

LK Li, BSc (Hons) Physiotherapy

TCL Tsang, BSc (Hons) Physiotherapy

Department of Rehabilitation Sciences, Hong Kong Polytechnic University, Hunghom, Hong Kong

* Corresponding author: tamis.pin@polyu.edu.hk

This paper was presented as a poster at the Hong Kong Physiotherapy Association Conference 2015, Hong Kong on 3-4 November 2015.

New knowledge added by this stud

- These results are the first published findings on clinical transition for adolescents with developmental disabilities in Hong Kong.

- Dissatisfaction with the adult health services and reluctance to change were the main barriers to clinical transition.

- The concerns and needs of the families were similar regardless of whether adolescents had physical or cognitive disabilities.

Implications for clinical practice or policy

- A structured clinical transition service is required for adolescents with developmental disabilities and their parents.

- Further in-depth studies are required to examine the needs for and concerns about clinical transition for all those involved. This should include adolescents with developmental disabilities, their parents or caregivers, and service providers in both paediatric and adult health services.

\section{Introduction}

Advances in medical management now enable children with developmental disabilities (DD) who may previously have died to live well into adulthood. ${ }^{1}$ Such disabilities are defined as any condition that is present before the age of 22 years and due to physical or cognitive impairment or a combination of both that significantly affects selfcare, receptive and expressive language, mobility, learning, independent living, or the economic independence of the individual. ${ }^{2}$ The transition from adolescence to adulthood is a critical period 


\section{香港對於有發展障礙的青少年臨床過渡的 初步研究}

邊慧敏、陳立新、陳創林、傳家禧、馮浩榮、李立喬、曾頌靈

引言：有發展障礙的兒童滿 18 歲後會從兒童及青少年科轉移至成人科 健康服務。香港對於這臨床過渡階段所提供的服務很分散, 目前也沒 有關於受影響青少年及其家屬在這過渡階段的本地研究數據。這初步 研究旨在探索並搜集關於有發展障礙的青少年及其家屬從兒童及青少 年科轉移至成人科健康服務的初步數據。

方法：這探索性研究於香港兩間特殊學校內進行。研究人員以廣東話 進行問卷調查, 對象為有發展障礙的青少年及其家屬, 然後以描述性 統計來分析封閉式問題的回答, 並總結開放式問題的回應。

結果：研究中有 22 名父母 (平均年齡49.9歲, 標準差10.0歲) 和 13 名 青少年 (平均年齡 19.6歲, 標準差 1.0歲) 透過面訪完成問卷。有發展 障礙的青少年主要診斷為腦㿏（59\%）和認知功能障礙（55\%）。受 訪父母中有 $77 \%$ 不願意從兒童及青少年科轉移至成人科健康服務。10 名已轉移至成人科健康服務的青少年病例中， $60 \%$ 的父母對於所提供 的服務感到不滿, 主要原因是不願意改變和不滿成人科所提供的健康 服務。他們認為臨床過渡期充滿挑戰, 所以為他們提供有系統的轉移 服務是相當重要的。

結論：這是對於有發展障礙的青少年及其家屬從兒童及青少年科轉移 至成人科健康服務的初步數據的首項研究。進一步研究或有助了解他 們在臨床過渡期間的需要。 for all young people. ${ }^{3}$ In a clinical context, adult transition is "the purposeful, planned movement of adolescents and young adults with chronic physical and medical conditions from child-centered to adultoriented health-care systems". In 2001, a consensus statement with guidelines was endorsed to ensure adolescents with DD, who depend on coordinated health care services, make a smooth transition to the adult health care system in order to receive the services that they need in developed countries such as the United States. ${ }^{5}$

Researchers have identified needs and factors necessary for the successful transition of adolescents with DD ${ }^{6,7}$ From the adolescent's perspective, barriers to success include their dependence on others, reduced treatment time and access to specialists in the adult health service, lack of information about transition, and lack of involvement in the decision-making process. Parents of adolescents with DD were reluctant or confused about changing responsibilities during the transition period. The majority of challenges came from the service systems and included unclear eligibility criteria and procedures, limited time and lack of carer training, fragmented adult health service provision, lack of communication between service providers, and inaccessibility to resources including information. ${ }^{6,7}$

Based on the 2015 census of 'Persons with disabilities and chronic diseases in Hong Kong' from the Hong Kong Census and Statistics Department, there were 22100 (3.8\%) people with disability (excluding cognitive impairment) aged between 15 and 29 years, ie who were transitioning from the paediatric to adult health service. ${ }^{8}$ According to the Hospital Authority, Hong Kong, all public hospitals, and specialist and general out-patient clinics are organised into seven hospital clusters based on geographical location. ${ }^{9}$ The Duchess of Kent Children's Hospital (DKCH) is a tertiary centre that provides specialised services for children with orthopaedic problems, spinal deformities, cerebral palsy and neurodevelopmental disorders, and neurological and degenerative diseases. Unlike overseas health care, there is no children's hospital in Hong Kong that provides an acute health service. All paediatric patients go to the same hospital as adult patients but are triaged into the paediatric section for management by both in-patient and out-patient services. The specialised out-patient clinic list under each hospital cluster varies. Children with DD might receive services from general paediatrics clinic, a cerebral palsy clinic, Down's clinic, behavioural clinic, or paediatric neurology out-patient clinic. Once a child reaches the age of 18 years, they are referred to the adult section of the same hospital for continued care. They will be followed up in neurology or movement disorder clinics, where other patients with adult-onset neurological conditions or movement disorders, such as stroke, Parkinson's disease, multiple sclerosis are followed up. There is no separate specialised clinic for complex childonset DD. ${ }^{10}$

Although adult transition for adolescents with DD has been recognised as a crucial area in health care overseas, it is an under-developed service in Hong Kong. ${ }^{11}$ A local study found that there is a service gap in adult transition for young people with chronic medical conditions, such as asthma, diabetes, and epilepsy. Training and education are urgently required for both service providers and young people with chronic health conditions and their families. ${ }^{11}$ It is unclear if the challenges and barriers identified in overseas literature ${ }^{6,7}$ are applicable to Hong Kong, where the paediatric and adult health services, especially the medical services, are located in the same building. At present, no study has been conducted with adolescents with DD and their families in Hong Kong about the issues they face during clinical transition. As a start, in this pilot study, we aimed to explore the acceptance of clinical transition and identify the main barriers to successful clinical transition for adolescents with DD and their caregivers in Hong Kong.

\section{Methods}

\section{Participants}

A survey study was conducted on a convenience 
sample of adolescents and/or their caregivers, who were recruited from two special high schools (Hong Kong Red Cross John F Kennedy Centre [JFK] and Haven of Hope Sunnyside School [HOH]) in Hong Kong. Students from JFK have primarily physical and multiple disabilities including cerebral palsy or muscular dystrophy and those from $\mathrm{HOH}$ have severe cognitive impairment. Both schools provide rehabilitation services on site including physiotherapy, occupational therapy, speech therapy, nursing support, and family support via the school social workers. The medical out-patient services for the students fall under different hospital clusters, depending on where the students' families live. The parents are responsible for taking their adolescent children for medical review. As there was no previous study on which basis to calculate the required sample size and as a pilot study, we aimed to recruit 10 adolescents and their parents/ caregivers in each school.

The inclusion criteria of the adolescents were: (1) aged 16 to 19 years and (2) a diagnosis of DD. All participating adolescents and/or their parents or legal guardians gave written informed consent before the survey. For adolescents with severe cognitive impairment, consent was sought from their parents as proxy and only their parents participated in the survey. This pilot study was approved by the Human Subjects Ethics Sub-committee of the Hong Kong Polytechnic University.

\section{Survey}

A specific questionnaire was developed for this pilot study to collect information relative to: (1) demographic characteristics of the participants; (2) whether or not the study participants were aware of the transition and the information source(s); (3) if the study participants were willing to transition to the adult health service and the underlying reasons; (4) for those who had transitioned, if they were satisfied with the adult health service and the underlying reasons; and (5) the opinion of the study participants of the clinical transition service. As a pioneer pilot study, health service included both medical and rehabilitation services and the study aimed to explore the general issues faced by this group of adolescents and their families during clinical transition. Lastly, as we predicted that the competency level of the adolescents and their caregivers in managing their disabilities might influence their perception of clinical transition, information about their self-rated competency level was also collected. Questions in the latter part were based on information from the Adolescent Transition Care Assessment Tool and were designed to assist health care professionals to provide a better transition for adolescents with chronic illness. ${ }^{12}$ The whole survey was administered by interviewers for the study adolescents and/or their caregivers separately in Cantonese. All interviews were recorded for data analyses.

The survey comprised closed- and open-ended questions. The closed-ended questions were designed to require a dichotomous answer, ie 'yes' or 'no', or an answer from a set of choices. For example, when asked about the sources of information about clinical transition, the study participants could choose their answers from a list of professionals such as paediatricians, social workers, physiotherapists, and school teachers. The open-ended questions focused on the reasons for an earlier response. For example, when asked if they wished to move to the adult health service, the individual would first answer 'yes' or 'no', then give their reasons. For the questions about selfperceived competency level, study participants read a number of statements ( 8 for the adolescents and 14 for parents) and indicated how much they agreed with the statement using a Likert-scale from 'strongly disagree' to 'strongly agree'.

\section{Data analyses}

Descriptive statistics-including mean, median, standard deviation, or quartiles-were used to analyse the responses to the closed-ended questions. Discussion of the open-ended questions was transcribed and summarised by five team members (CLC, KHF, KHWF, LKL, and TCLT). The content was analysed and themes were identified independently by two other team members (TWP and WLSC). These themes were discussed and a consensus reached by all team members.

\section{Results}

Thirteen potential families were approached at the JFK via the physiotherapist of the school anticipating possible refusal by some. All the students and their parents agreed to participate, so all were included. Ten families were approached at the $\mathrm{HOH}$ via the social worker at the school but one parent declined the offer and no other family was interested in participating in the study. Since the students from $\mathrm{HOH}$, who were cognitively impaired, were not able to be interviewed, only their parents/caregivers were interviewed. As a result, 22 parents (13 from the JFK and 9 from the $\mathrm{HOH}$ ) and 13 adolescents (all from the JFK) were asked to complete the face-to-face survey. The demographic data of the participants are listed in Table 1. Cerebral palsy and cognitive impairment were the principal types of DD. All adolescents received rehabilitation from the Hospital Authority and/or from their special school. All the adolescents accessed between four and seven paediatric medical specialists (eg paediatrician, neurologist, orthopaedic surgeon) and rehabilitation services (eg physiotherapy, occupational therapy, speech therapy) indicating their complex needs. 
Over $90 \%$ of the JFK students were followed up at the $\mathrm{DKCH}$ that is within walking distance of the school (personal communication, Senior Physiotherapist at JFK).

Table 2 summarises the participant responses about clinical transition. The majority of the parents (77\%) and adolescents (85\%) knew that clinical transition to adult care would occur at 18 years of age. They were mainly informed by their paediatrician (50\% of parents and $69 \%$ of adolescents). Most parents $(77 \%)$ were reluctant to make this move. Ten parents stated that their adolescent child was already receiving care from the adult sector and over half of them $(60 \%)$ were dissatisfied with the service. Four of the 13 adolescents clearly stated that they had transitioned to the adult health service during the survey and all of them were happy with the transition. Among those 17 families who knew that clinical transition to adult care would occur at 18 years of age, 10 adolescents were all over 18 years old, whereas those in another seven (41\%) families were also over 18 years old and still receiving services from the paediatric sector at the time of the study.

When asked why they were not willing to the transition or why they were dissatisfied after the transition, the parent responses could be summed up as two main areas of concern: reluctance to change and dissatisfaction with the adult health services. Most parents (16/22, 73\%) did not want to change their existing care circumstances. When asked why, some parents cited dissatisfaction with the adult health service or health system (for the latter, $13 / 22,59 \%$ of parents). For example, parents found it difficult to attend the follow-up appointments using public transport. Although there was a free shuttle bus service for families who needed it, parents were frustrated by the limited service.

Some parents also wanted more flexible visiting hours in the adult hospital so that they could look after their adolescent children, especially those who were cognitively impaired. The parents worried about the quality of care for their children who were entirely dependent for their daily activities. They were also unhappy about the waiting time for medical appointments and stated that their children with DD had a short attention span and were unable to control their behaviour. Long waiting times in a crowded waiting area, which is commonly observed in the adult setting, could easily trigger their behavioural problems.

There was also dissatisfaction with the adult health service providers (13/22, 59\% of parents). Parents often found that the adult medical staff demonstrated limited understanding and knowledge of their child's clinical presentation and abilities, especially for those with severe cognitive impairment. The adult health service providers did not know how to communicate with the cognitively
TABLE I. Demographic information of study participants

\begin{tabular}{|c|c|}
\hline Demographics & Data* \\
\hline \multicolumn{2}{|l|}{ Interviewee relationship with study adolescents } \\
\hline Father & $7(32)$ \\
\hline Mother & $13(59)$ \\
\hline Grandmother & $1(5)$ \\
\hline Sister & $1(5)$ \\
\hline \multicolumn{2}{|l|}{ Age (years) } \\
\hline Adolescents & $19.6 \pm 1.0$ \\
\hline$\leq 18$ years & $5(23)$ \\
\hline$>18$ years & $17(77)$ \\
\hline Parents / guardians & $49.9 \pm 10.0$ \\
\hline \multicolumn{2}{|l|}{ Parent's / guardian's education level } \\
\hline Primary school & $2(9)$ \\
\hline High school & $11(50)$ \\
\hline Diploma or equivalent & $3(14)$ \\
\hline Degree or equivalent & $6(27)$ \\
\hline \multicolumn{2}{|l|}{ Types of developmental disabilities } \\
\hline Cerebral palsy & $13(59)$ \\
\hline Cognitive impairment & $12(55)$ \\
\hline Language delay & $9(41)$ \\
\hline Developmental delay & $8(36)$ \\
\hline Visual impairment & $7(32)$ \\
\hline Dyslexia & $6(27)$ \\
\hline Attention deficit hyperactivity disorder & $3(14)$ \\
\hline Hearing impairment including deafness & $3(14)$ \\
\hline Muscular dystrophy & $3(14)$ \\
\hline Others & $7(32)$ \\
\hline \multicolumn{2}{|l|}{ Main caregivers } \\
\hline Parents & $20(91)$ \\
\hline Grandparents & $3(14)$ \\
\hline Siblings & $2(9)$ \\
\hline Domestic helpers & $9(41)$ \\
\hline Others & $3(14)$ \\
\hline Time spent in caring activities (hours/day) & $13.1 \pm 10.0$ \\
\hline Time in accessing paediatric services (years) & $15.1 \pm 4.9$ \\
\hline \multicolumn{2}{|l|}{ Person accompanying to paediatric services } \\
\hline Parents / guardians & $22(100)$ \\
\hline Self & 0 \\
\hline
\end{tabular}

impaired adolescents and treated them as other normal adults.

There is no formal clinical transition service in Hong Kong but when asked, the majority of parents $(21 / 22,95 \%)$ and adolescents $(11 / 13,85 \%)$ stated that they would welcome such a service. About two 
TABLE 2. Summary of responses to questions about clinical transition

\begin{tabular}{|c|c|c|}
\hline Response to questions & Parents/guardians $(n=22)^{\star}$ & Adolescents $(n=13)^{*}$ \\
\hline \multicolumn{3}{|l|}{ Knowledge on transition to adult health services after 18 years of age } \\
\hline Yes & $17(77 \%)$ & $11(85 \%)$ \\
\hline No & $5(23 \%)$ & $2(15 \%)$ \\
\hline \multicolumn{3}{|l|}{ Sources of this information } \\
\hline Medical doctor & $11(50 \%)$ & $9(69 \%)$ \\
\hline Therapist & $1(5 \%)$ & $1(8 \%)$ \\
\hline Social worker & $2(9 \%)$ & 0 \\
\hline Peers & $3(14 \%)$ & $1(8 \%)$ \\
\hline Leaflet & 0 & 0 \\
\hline Internet & 0 & 0 \\
\hline Others & $4(18 \%)$ & $2(15 \%)$ \\
\hline Missing data & $1(5 \%)$ & 0 \\
\hline Willingness to transition to adult health service & & - \\
\hline Yes & $2(9 \%)$ & \\
\hline No & $17(77 \%)$ & \\
\hline No comment & $3(14 \%)$ & \\
\hline Feelings about transitioning to adult health services & - & \\
\hline Happy & & $4(31 \%)$ \\
\hline No feeling & & $4(31 \%)$ \\
\hline Unwilling & & $2(15 \%)$ \\
\hline Confused & & $1(8 \%)$ \\
\hline Others & & $2(15 \%)$ \\
\hline \multicolumn{3}{|l|}{ Currently receiving adult health services } \\
\hline Yes & $10(45 \%)$ & $4(31 \%)$ \\
\hline No & $12(55 \%)$ & $8(62 \%)$ \\
\hline Not sure & 0 & $1(8 \%)$ \\
\hline $\begin{array}{l}\text { Among those adolescents who had transitioned to the adult health service in the } \\
\text { survey }\end{array}$ & Parents/guardians $(n=10)$ & Adolescents $(n=4)$ \\
\hline \multicolumn{3}{|l|}{ Adult health services accessed } \\
\hline Medical specialties & $9(90 \%)$ & $4(100 \%)$ \\
\hline Physiotherapy & $3(30 \%)$ & $2(50 \%)$ \\
\hline Occupational therapy & $3(30 \%)$ & $2(50 \%)$ \\
\hline Speech therapy & $1(10 \%)$ & 0 \\
\hline Clinical psychology & $1(10 \%)$ & 0 \\
\hline Social work & 0 & $1(25 \%)$ \\
\hline Dietetics & 0 & 0 \\
\hline \multicolumn{3}{|l|}{ Satisfaction with adult health services } \\
\hline Yes & $3(30 \%)$ & $4(100 \%)$ \\
\hline No & $6(60 \%)$ & 0 \\
\hline No comment & $1(10 \%)$ & 0 \\
\hline
\end{tabular}

* Because of rounding, not all percentages total 100

thirds of the study parents and adolescents $(23 / 35$, and adult health services, providing information $66 \%)$ would like the clinical transition service to about available services in the adult sector. support them during the clinical transition. About The Figure summarises the responses of one third of the parents $(7 / 22,32 \%)$ believed that the adolescents for self-perceived competency in service could act as a bridge linking the paediatric managing their disability, and Table 3 summarises 


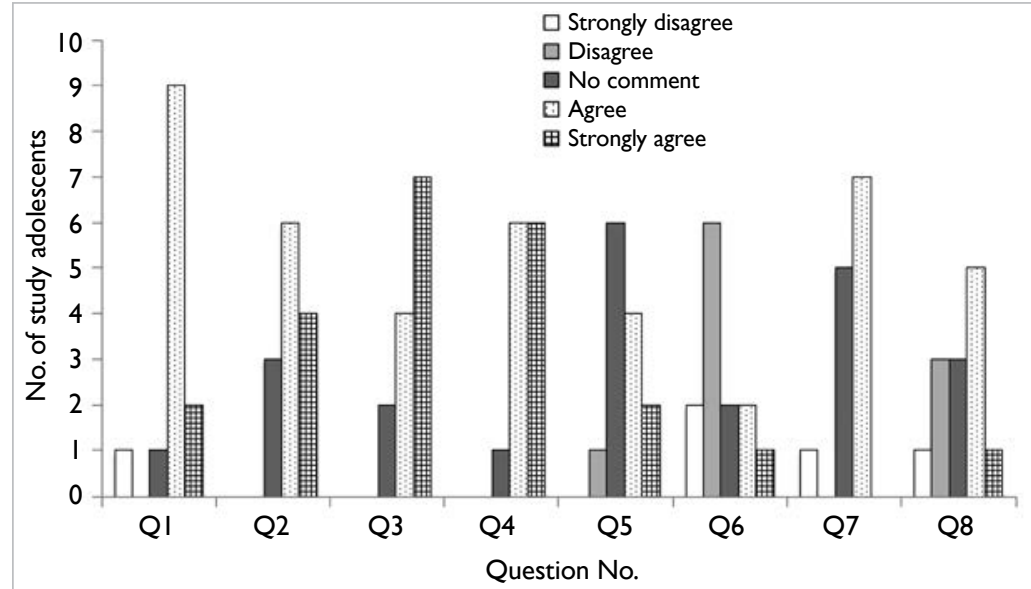

FIG. Responses of study adolescents about their self-perceived competency in managing their disability

Q I I can understand the explanations/instructions from medical staff

Q2 I can explain my conditions to medical staff

Q3 I understand the impacts of disease to my future

Q4 I understand the importance of therapy to my health condition at this instant/in the future

Q5 I can seek help from different medical specialties based on my health condition

Q6 I can attend medical appointment by myself

Q7 I can make medical decision by myself

Q8 I worry that the medical staff in adult health services are not familiarised with my medical history the study parents' responses. Most adolescents demonstrated understanding of instructions $(11 / 13$, $85 \%)$, confidence in communicating with the service providers about their condition $(10 / 13,77 \%)$, and understanding the importance of treatments for their condition (12/13, 92\%) [Fig]. About half were confident in seeking help from different specialties according to their condition $(6 / 13,46 \%)$ and making medical decisions $(7 / 13,54 \%)$ [Fig]. Over half of the adolescents, however, lacked the confidence to attend routine medical visits on their own (8/13, $62 \%)$ and worried about the unfamiliar adult medical service $(6 / 13,46 \%)$ [Fig]. Most parents stated that they were familiar with their children's medical conditions and treatments (20/22, 91\%) and able to seek help from different medical specialties based on their child's condition $(14 / 22,64 \%)$ [Table 3]. Only a minority of parents $(1 / 22,5 \%)$, however, believed that their children were capable of attending medical appointments on their own. Less than half of the parents believed that their children would be able to explain their medical condition $(9 / 22,41 \%)$ or make independent clinical decisions in the future $(7 / 22$, $32 \%)$. None of the parents of an adolescent with

TABLE 3. Summary of responses of study parents about their self-perceived competency in managing the disability*

\begin{tabular}{|c|c|c|c|c|c|c|}
\hline \multirow[t]{2}{*}{ Question No.† } & \multicolumn{2}{|c|}{ Strongly disagree / disagree } & \multicolumn{2}{|c|}{ No comment } & \multicolumn{2}{|c|}{ Strongly agree / agree } \\
\hline & JFK & $\mathrm{HOH}$ & JFK & $\mathrm{HOH}$ & JFK & $\mathrm{HOH}$ \\
\hline Q1 & 0 & 0 & 2 & 0 & 11 & 9 \\
\hline Q2 & 0 & 0 & 1 & 0 & 12 & 9 \\
\hline Q3 & 0 & 0 & 0 & 0 & 13 & 9 \\
\hline Q4 & 0 & 0 & 1 & 0 & 12 & 9 \\
\hline Q5 & 3 & 2 & 2 & 1 & 8 & 6 \\
\hline Q6 & 3 & 5 & 4 & 1 & 6 & 3 \\
\hline Q7 & 0 & 0 & 0 & 0 & 13 & 9 \\
\hline Q8 & 2 & 1 & 4 & 5 & 7 & 3 \\
\hline Q9 & 9 & 9 & 3 & 0 & 1 & 0 \\
\hline Q10 & 6 & 9 & 7 & 0 & 0 & 0 \\
\hline Q11 & 3 & 9 & 4 & 0 & 6 & 0 \\
\hline Q12 & 2 & 9 & 2 & 0 & 9 & 0 \\
\hline Q13 & 4 & 9 & 6 & 0 & 3 & 0 \\
\hline Q14 & 2 & 9 & 4 & 0 & 7 & 0 \\
\hline
\end{tabular}

Abbreviations: $\mathrm{HOH}=$ Haven of Hope Sunnyside School; JFK = Hong Kong Red Cross John F Kennedy Centre

* JFK ( $n=13)$ and $\mathrm{HOH}(n=9)$

+ Questions:

QI I can understand my child's health condition

Q2 I can explain my child's conditions to medical staff

Q3 I understand the impacts of disease to my child's future

Q4 I understand the importance of therapy to my child's health condition at this instant/in the future

Q5 I am able to seek help from different medical specialties based on my child's health condition

Q6 The communication among different medical professions is enough

Q7 I believe I can accompany my child to attend medical appointment at this moment

Q8 I believe I can accompany my child to attend medical appointment in the coming 10 years

Q9 I believe my child can attend medical appointment by himself/herself at this moment

QI0 I believe my child will be able to attend medical appointment by himself/herself in the future

QII I believe my child is able to explain his/her condition to medical staff at this moment

Q12 I believe my child will be able to explain his/her condition to medical staff in the future

Q13 I believe my child is able to make medical decision at this moment

Q14 I believe my child will be able to make medical decision in the future 
cognitive impairment believed that the child would ever be able to manage their own health.

\section{Discussion}

The present pilot study aimed to determine how adolescents with DD and their parents in Hong Kong accept the clinical transition and identify the main barriers to successful transition. This was the first step to understanding the issues of this population group during clinical transition and to enable planning for the future. As far as we know, this study is the first to be conducted in Hong Kong for this population group. Overall, 22 parents and 13 adolescents were recruited from two special schools (one for primarily physically disabled children and the other for severe physically and/or cognitively impaired individuals), aiming to understand what was the acceptance level and barriers faced by these two vastly different groups with $\mathrm{DD}$. The results were very similar between these two subgroups, indicating that the study parents had similar issues during clinical transition, regardless of the type of DD of their child. Hence, the results from these two subgroups were discussed as one group.

Most of the study participants were aware of the clinical transition necessary at the age of 18 years. Only $10(45 \%)$ of the 22 families shifted to the adult health service, despite the fact that their adolescent child was close to or over 18 years old (Tables 1 and 2). The reasons for this delay were not thoroughly explored but it has been suggested that medical practitioners in the paediatric service felt that the adolescents were not ready for the transition so they continued to see them well into adulthood while the parents and the adolescents were reluctant to make the move. ${ }^{11}$ The latter appeared to be true because when asked, most study participants did not want to change and move to the adult health service. This contradicts the results of a previous local study of adolescents with chronic medical conditions, in which over $80 \%$ of the study participants (adolescents and parents) were willing to move to the adult health service. ${ }^{11}$ The difference is likely due to the complexity of the health conditions of the present cohort. Adolescents with DD usually have varying degrees of physical and/or cognitive impairment and so depend more on others for managing their health condition, making them and their carers more anxious about any change. ${ }^{6,7}$ For those with chronic medical conditions, the physical and cognitive abilities of the adolescent were unlikely affected and hence the adolescents could manage their condition more independently and more readily after the transition. ${ }^{13}$ This speculation was supported by the findings about self-perceived competency level. Most study adolescents, who had mainly physical disabilities, were not confident about attending a medical appointment alone because of their limited physical abilities (Fig). The reluctance for change may also be due to fear of the unknown and of not being well prepared. ${ }^{11}$ In Hong Kong, clinical transition is non-structured and unplanned. ${ }^{11}$ Parents are often informed just before the transition, leading to poor preparation and confusion. Early and continuous clinical transition from early adolescence can enable parents and adolescents with DD to be prepared and actively participate in the transition planning. ${ }^{7,14}$ Although the clinical transition service is not wellknown in Hong Kong, the study participants had a positive attitude towards a clinical transition service to help them navigate the process by bridging the paediatric and adult health services. In addition, the study parents wished to have more information about available adult health services, eg rehabilitation services, wheelchair maintenance services, etc. More information about the unknown has been shown to reduce the reluctance of parents and adolescents to change and to further improve their confidence about moving to adult care. ${ }^{5,6,15,16}$

Another barrier was dissatisfaction with the health care system and service providers in the adult setting (Table 2), and is in line with present literature. ${ }^{7}$ Some parents found it difficult to arrange transport to the adult hospital for follow-up while most of the appointments were currently at the special school. More accessible public transport might help, especially in Hong Kong, where private vehicles are not a common option. Flexible visiting hours in the adult hospital that would enable parents to care for their dependent adolescent child may also reduce their dissatisfaction. Longer waiting times for medical appointments in the adult setting was frequently mentioned by the study parents. In the adult sector, patients with all kinds of neurological conditions, both child-onset and adult-onset, are reviewed in the same clinic. The number of patients attending the clinic is vastly increased compared with the paediatric setting. In addition, patients with adult-onset neurological conditions and their family may not understand the characteristics of DD. Stressed behaviour of an adolescent child with DD may be perceived by other families as impatience. In the paediatric clinic, where all clinic attendees were children or adolescents with DD and their parents, the waiting time was shorter. Families as well as clinic staff had a full understanding of DD and would be more tolerant. It is likely that this lack of support in the adult setting further discouraged the study parents to make the transition willingly. Changes to the existing health care system, such as a separate clinic for child-onset DD conditions, may be a possible small step to assist this group in making a smooth transition. Education about clinical transition for staff in both the paediatric and adult settings allows them to prepare the families in advance. Education about paediatric conditions and 
communication with adolescents with DD can also equip adult staff with confidence so they develop a strong rapport with the families. ${ }^{16}$

Interestingly, from the perspective of the adolescents, the four adolescents who had transitioned stated that they were happy with the adult health service. Two (50\%) adolescents indicated that because the 'new' doctors did not know them well, they paid more attention to them and one adolescent did not give any reason to support his statement. It is likely that in the paediatric sector, these adolescents had been followed up from early childhood by the same medical staff who virtually watched them grow up. A change of scene and people in the adult sector is welcomed by these adolescents. In addition, they might welcome the idea that they have started to actively participate in the consultation as a 'patient', unlike in the paediatric sector, where the consultation was directed at their parents, not them. ${ }^{14}$

Parents of adolescents who had physical and/ or cognitive impairment had a similar perception of their adolescent child, that they would never be able to attend a medical appointment alone, presumably because of their disability (responses to questions 9 to 10 in Table 3). None of the parents of a cognitively impaired adolescent child believed their child to be capable of explaining their medical condition to others or making an independent medical decision. On the contrary, parents of a physically disabled child thought that while it may not apply at present, their child would be able to make their own decisions in future (responses to questions 11 to 14 in Table 3). Nonetheless, there was a discrepancy in this perception between the study adolescents and parents (Fig and Table 3). Most adolescents believed they could explain their condition to others (question 2 in the Fig) and over half believed that they could make an independent medical decision at the time of the study (question 7 in the Fig). Further studies are needed to determine whether this discrepancy is due to confusion on the part of the parents because of changing responsibilities during the transition. ${ }^{13}$ While western literature emphasises the importance of active participation by adolescents during clinical transition, ${ }^{14}$ it would be interesting to see if this can be endorsed in a parent-dominant Chinese society such as Hong Kong, where cultural differences may influence attitudes towards clinical transition. ${ }^{17}$

We were unable to analyse other challenges identified in overseas literature, such as unclear eligibility criteria and procedures and limited time for clinical transition, because comparable data were not available for Hong Kong. In other developed countries, adolescents are shifted with the assistance of a clinical transition service based in the children's hospital (if any) or by applying clinical guidelines for best service. ${ }^{18}$ In Hong Kong, adolescents are referred from the paediatric section to the adult section within the same hospital. Each hospital cluster may have different procedures for this 'transition' and there is no defined department within the hospital structure to assist adolescents and their families through this process. Nor do the families receive any advice about how to negotiate this process. A future in-depth study is recommended to understand the existing situation of clinical transition in different hospital clusters and determine how to establish a more formal approach among all the hospital clusters in Hong Kong to support this group of adolescents and their families during this confusing time.

\section{Limitations of the present study}

There may have been a selection bias in the study sample as the families were approached by convenience through the school staff. Due to the small sample size, no statistical analysis was conducted to compare the subgroups of adolescents with physical and cognitive impairments. Although the sample size was small, the purpose of the present pilot study was not to generalise the findings to all adolescents with DD but to begin to understand the acceptance of clinical transition and the main barriers to success for adolescents with DD and their family in Hong Kong. The present results are also in line with the literature in this area. ${ }^{4,7,11,14,17}$ Future studies with a larger sample size and more in-depth qualitative data are required to verify the present results. The potential subjective bias of the results, especially for the open-ended questions, was another limitation but we attempted to minimise this through consensus agreement among the team.

\section{Conclusions}

In the present explorative study, close to half of the study families had a delayed clinical transition to the adult health service. Most study parents were reluctant for their adolescent children to shift to the adult health service due to unwillingness to change and dissatisfaction with the adult medical service. A structured and well-planned clinical transition was urged by the study participants to bridge the paediatric and adult health services and to provide support to the family. Further studies are required to analyse the needs and concerns of adolescents with DD and their families as well as the service providers in the adult medical setting to facilitate the future development of a clinical transition service in Hong Kong.

\section{Acknowledgements}

The authors would like to thank all the participating families from the Hong Kong Red Cross John F Kennedy Centre and Haven of Hope Sunnyside School. 


\section{Declaration}

All authors have disclosed no conflicts of interest.

\section{References}

1. Westbom L, Bergstrand L, Wagner P, Nordmark E. Surviva at 19 years of age in a total population of children and young people with cerebral palsy. Dev Med Child Neurol 2011;53:808-14.

2. Public Law 98-527, Developmental Disabilities Act of 1984.

3. Staff J, Mortimer JT. Diverse transitions from school to work. Work Occup 2003;30:361-9.

4. Blum RW, Garell D, Hodgman $\mathrm{CH}$, et al. Transition from child-centered to adult health-care systems for adolescents with chronic conditions. A position paper of the Society for Adolescent Medicine. J Adolesc Health 1993;14:570-6.

5. American Academy of Pediatrics, American Academy of Family Physicians, American College of PhysiciansAmerican Society of Internal Medicine. A consensus statement on health care transitions for young adults with special health care needs. Pediatrics 2002;110(6 Pt 2):13046.

6. Bindels-de Heus KG, van Staa A, van Vliet I, Ewals FV, Hilberink SR. Transferring young people with profound intellectual and multiple disabilities from pediatric to adult medical care: parents' experiences and recommendations. Intellect Dev Disabil 2013;51:176-89.

7. Stewart D, Stavness C, King G, Antle B, Law M. A critical appraisal of literature reviews about the transition to adulthood for youth with disabilities. Phys Occup Ther Pediatr 2006;26:5-24.

8. Persons with disabilities and chronic diseases in Hong Kong. Hong Kong: Hong Kong Census and Statistics Department; 2016. Available from: http://www.statistics. gov.hk/pub/B71501FB2015XXXXB0100.pdf. Accessed Jul 2016.

9. Clusters, hospitals \& institutions. Hospital Authority. 2016. Available from: http://www.ha.org.hk/visitor/ha visitor index.asp?Content ID $=10036 \&$ Lang=ENG\&Dime nsion=100\&Parent_ID=10004. Accessed Jul 2016.

10. Hospital Authority Statistical Report 2012-2013. Hong Kong: Hospital Authority; 2013.

11. Wong LH, Chan FW, Wong FY, et al. Transition care for adolescents and families with chronic illnesses. J Adolesc Health 2010;47:540-6.

12. Hong Kong Society for Adolescent Health. Adolescent Transition Care Assessment Tool, Public Education Series No. 12 (2013). Available from: http://hksah.blogspot. hk/2013/11/adolescent-transition-care-assessment.html. Accessed 6 Feb 2016

13. Stewart DA, Law MC, Rosenbaum P, Willms DG. A qualitative study of the transition to adulthood for youth with physical disabilities. Phys Occup Ther Pediatr 2002;21:3-21.

14. Viner RM. Transition of care from paediatric to adult services: one part of improved health services for adolescents. Arch Dis Child 2008;93:160-3.

15. Blum RW. Introduction. Improving transition for adolescents with special health care needs from pediatric to adult-centered health care. Pediatrics 2002;110(6 Pt 2):1301-3.

16. Stewart D. Transition to adult services for young people with disabilities: current evidence to guide future research. Dev Med Child Neurol 2009;51 Suppl 4:169-73.

17. Barnhart RC. Aging adult children with developmental disabilities and their families: challenges for occupational therapists and physical therapists. Phys Occup Ther Pediatr 2001;21:69-81.

18. Department of Health. National Service Framework for Children, Young People and Maternity Services. Transition: getting it right for young people. Improving the transition of young people with long term conditions from children's to adult health services. 2006. Available from: http://dera. ioe.ac.uk/8742/1/DH_4132145\%3FIdcService\%3DGET_FI LE\%26dID\%3D23915\%26Rendition\%3DWeb. Accessed Jul 2016. 